\title{
Predictive Value of Estimated Glomerular Filtration Rate for the Prognosis of Elderly Patients With Acute Myocardial Infarction
}

\author{
Namkyun Kim², Hun Sik Park ${ }^{1}$, Jae Yong Yoon ${ }^{1}$, Hyun Jun Cho ${ }^{1}$, Chang-Yeon Kim², Jae-Hyung Roh', \\ Myung Hwan Bae ${ }^{1}$, Jang Hoon Lee ${ }^{1}$, Dong Heon Yang ${ }^{1}$, Yongkeun Cho ${ }^{1}$, Shung Chull Chae ${ }^{1}$, Jihyun Sohn ${ }^{2}$, \\ Se Yong Jang ${ }^{2}$ \\ ${ }^{1}$ Department of Internal Medicine, ${ }^{2}$ Cardioloy Center, Kyungpook National University Hospital, Daegu, Korea
}

Corresponding Author:

Hun Sik Park, MD

Department of Internal Medicine, Kyungpook National University

Hospital, Kyungpook National University School of Medicine, 130 Dongdeok-ro, Jung-gu, Daegu 41944, Korea

Tel: $+82-53-420-5529$

Fax: +82-53-424-6721

E-mail: hspark@knu.ac.kr

Received: November 28, 2016 Revised: February 7, 2017 Accepted: February 11, 2017
Background: The aim of this study was to investigate the predictive value of estimated glomerular filtration rate (eGFR) calculated with the simplified Modification of Diet in Renal Disease (MDRD) Study and Chronic Kidney Disease Epidemiology Collaboration (CKD-EPI) equations for prognosis in elderly patients with acute myocardial infarction (AMI). Methods: This study included 1,372 patients (mean age, 64.2 \pm 11.8 years; men, 67.9\%) entered in the Kyungpook National University Hospital Acute Myocardial Infarction Registry from November 2005 to February 2010. We analyzed 1-year major adverse cardiac events (MACE) according to the eGFR calculated with the simplified MDRD Study and CKD-EPI equations. Results: The mean eGFR values calculated with the MDRD Study and CKD-EPI equations were 81.3 \pm 44.4 and $78.5 \pm 27.1 \mathrm{~mL} /\left(\mathrm{min} / 1.73 \mathrm{~m}^{2}\right)$, respectively. In receiver operating characteristic curve analysis for prediction of 1-year MACE, the area under the curve based on the CKD-EPI equation was greater than that using the MDRD Study equation (CKD-EPI equation VS. MDRD Study equation: 0.691 vs. $0.674, p=0.041$ ). Multivariate analysis using a Cox proportional hazards model revealed that the eGFR calculated with the CKD-EPI equation was an independent predictor of the occurrence of MACE within 1 year after AMI. However, eGFR calculated with the MDRD Study equation did not have predictive value. Furthermore, the eGFR calculated with the CKD-EPI equation had incremental prognostic value for established risk factors (chi-square=5.78, $p=0.016$ ). Conclusion: The eGFR calculated using the CKD-EPI equation was an independent predictor of 1-year MACE in elderly patients with AMI.

Key Words: Myocardial infarction, Glomerular filtration rate, Major adverse cardiac event

\section{INTRODUCTION}

Coronary artery disease including acute myocardial infarction (AMI) is the leading cause of death worldwide". Many factors are known to have substantial effects on the outcome of AMI. Renal failure is a powerful predictive factor for the outcome of AMl, even with mildly decreased renal function ${ }^{2,3}$. In patients with end-stage renal disease, as defined by a glomerular filtration rate (GFR) of $<10.0 \mathrm{~mL} /\left(\mathrm{min} / 1.73 \mathrm{~m}^{2}\right)$, the 2-year mortality rate after myocardial infarction (MI) is approximately $50 \%$, which is twofold higher than that in the general population ${ }^{4)}$. Therefore, precise assessment of kidney function is an important step in predicting the outcome of AMI.

GFR is the best index for evaluation of kidney function, but cannot be measured easily in clinical settings; hence, estimated GFR (eGFR) is calculated using equations. The Modification of Diet in Renal Disease (MDRD) Study equation has gained widespread acceptance, ${ }^{5,6)}$. However, the MDRD equation has limited accuracy; therefore, a new equation for use in eGFR was developed: the Chronic Kidney Disease Epidemiology Collaboration (CKD-EPI) creatinine equation. The CKD-EPI equation is more accurate than the MDRD Study equation, especially for estimating higher GFRs with less bias?.

The eGFR calculated with the MDRD Study equation proved to be a predictive indicator for major risk factors of cardiovascular complications after $\mathrm{AMI}^{2}$. However, whether 
eGFR calculated with the CKD-EPI equation could be a predictive indicator of prognosis in AMI is unclear. This study aimed to investigate the clinical use of eGFR calculated with the simplified MDRD Study and CKD-EPI equations for predicting long-term prognosis in elderly patients with AMI.

\section{MATERIALS AND METHODS}

The Kyungpook National University Hospital Acute Myocardial Infarction Registry (KNUH AMIR) is a Korean, retrospective, observational, single-center registry of AMI cases. All patients with ST-segment elevation myocardial infarction (STEMI) and non-STEMI (NSTEMI) were included in the study. AMI was diagnosed based on characteristic presentation, serial electrocardiographic changes suggestive of infarction, and increased cardiac enzyme levels ${ }^{8)}$.

\section{Study Design}

From November 2005 to February 2010, 1,372 patients with a final diagnosis of STEMI or NSTEMI were enrolled in the KNUH AMIR. This study was approved by the Institutional Review Board of the Kyungpook National University Hospital (2016-12-019). All NSTEMI or STEMI patients who visited Kyungpook National Hospital during the study period were included. Patients with missing data were excluded. We examined baseline patient demographic characteristics, initial presentation, initial vital signs, laboratory test results, echocardiographic findings, and medications used, including beta blockers, angiotensin-converting enzyme inhibitor/angiotensin receptor blockers, and statins.

\section{Study Variables}

Baseline patient clinical characteristics, including age, sex, and cardiovascular risk factors (hypertension, diabetes mellitus, dyslipidemia, and smoking status), were identified. Initial vital sign parameters included systolic blood pressure, diastolic blood pressure, and heart rate. The Killip classification of AMI was determined by cardiologists. Laboratory tests, including blood samples, were performed on admission, except for the lipid profile, which was measured after at least 8 hours of fasting. Left ventricular ejection fraction (LVEF) was measured with 2-dimensional echocardiography and the Simpson method during hospitalization.

\section{Assessing Renal Function}

We assessed eGFR by using the MDRD Study and CKD-EPI formulas based on the initial creatinine examination. The MDRD Study equation is as follows: estimated GFR $=175 \times$ standardized $\mathrm{Scr}^{-1.154} \times$ agg $^{-0.203} \times 1.212$ [if black] $\times 0.742$ [if female], where GFR is expressed in milliliters per minute per $1.73 \mathrm{~m}^{2}$ of body surface area and $\mathrm{Scr}$ is expressed in milligrams per deciliter ${ }^{6)}$. At an estimated GFR of $\geq 60 \mathrm{~mL} /\left(\mathrm{min} / 1.73 \mathrm{~m}^{2}\right)$, the MDRD study equation has higher bias and lower precision than at an estimated GFR of $<60 \mathrm{~mL} /\left(\mathrm{min} / 1.73 \mathrm{~m}^{2}\right)$. Racial bias also exists, as estimated GFR is less studied in Asian individuals" ${ }^{9}$. The CKD-EPI equation is as follows: estimated $\mathrm{GFR}=141 \times \min (S \mathrm{cr} / \kappa, 1)^{\mathrm{a}} \times \max (\mathrm{Scr} / \kappa, 1)^{-1.209} \times 0.993^{\mathrm{Age}} \times 1.018$ [if female] $\times 1.159$ [if black], where $S c r$ is the serum creatinine level, $\kappa$ is 0.7 for females and 0.9 for males, $a$ is -0.329 for females and -0.411 for males, min indicates the minimum of $S \mathrm{cr} / \mathrm{k}$ or 1 , and max indicates the maximum of $S \mathrm{cr} / \mathrm{k}$ or 1 . The CKD-EPI creatinine equation is more precise than the MDRD study equation for various populations and clinical conditions. One study suggested that the CKD-EPI equation could replace the MDRD Study equation for estimated GFR in routine clinical use ${ }^{9)}$.

Patients were categorized into 5 levels according to renal function: G1 (eGFR, $\left.\geq 90 \mathrm{~mL} /\left[\mathrm{min} / 1.73 \mathrm{~m}^{2}\right]\right), \mathrm{G} 2(60-89 \mathrm{~mL} /$ $\left.\left[\mathrm{min} / 1.73 \mathrm{~m}^{2}\right]\right), \mathrm{G} 3\left(30-59 \mathrm{~mL} /\left[\mathrm{min} / 1.73 \mathrm{~m}^{2}\right]\right), \mathrm{G} 4(15-29 \mathrm{~mL} /$ $\left.\left[\mathrm{min} / 1.73 \mathrm{~m}^{2}\right]\right)$, and $\mathrm{G} 5\left(<15 \mathrm{~mL} /\left[\mathrm{min} / 1.73 \mathrm{~m}^{2}\right]\right)$. The definition of decreased GFR according to the US National Kidney Foundation criteria for CKD was adopted: GFR $<60-89 \mathrm{~mL} /(\mathrm{min} /$ $1.73 \mathrm{~m}^{2}$ ) for more than 3 months $^{10}$.

\section{Study Outcomes}

We analyzed 1-year major adverse cardiac events (MACEs), defined as cardiac death, $\mathrm{Ml}$, and revascularization. Cardiac death was defined as death due to pump failure, arrhythmia, ventricular septal rupture, and free-wall rupture. MI was diagnosed by characteristic clinical presentation, serial changes on an electrocardiogram suggesting infarction, and an increase in cardiac enzymes. Revascularization included repeat percutaneous coronary intervention and coronary bypass graft for any reason. Follow-up data were obtained by reviewing medical records and telephone interviews with patients.

\section{Statistical Analysis}

As baseline characteristics, categorical variables were expressed as number with percentage, and differences between groups were analyzed by using the chi-square test. Continuous variables were expressed as mean \pm standard deviation and evaluated by using the independent t-test. To determine the factors predictive of 1-year cumulative MACE, multivariate Cox regression analyses were performed by using variables that were clinically significant $(p<0.05)$. Hazard ratios (HRs) and 95\% confidence intervals (Cls) were determined. All analyses were 2-tailed, with clinical significance defined as $p<0.05$. MedCalc ver. 12.5.0 (MedCalc, Ostend, Belgium) was used in receiver-operating characteristic (ROC) curve 
analysis for predicting 1-year MACE. The statistical software used for the analysis was IBM SPSS Statistics ver. 20.0 (IBM Co., Armonk, NY, USA).

\section{RESULTS}

\section{Baseline Characteristics}

We evaluated 1,372 patients with mean age $64.2 \pm 11.8$ years. Their baseline characteristics are shown in Table 1. Overall, 206 MACEs (15.2\%) occurred. The patients in the MACE group were older (age: $69.0 \pm 11.6$ years vs. $63.3 \pm 11.6$ years, $p<0.001)$, and had higher creatinine levels $(1.8 \pm 1.9$ $\mathrm{mg} / \mathrm{dL}$ vs. $1.0 \pm 0.9 \mathrm{mg} / \mathrm{dL}, \mathrm{p}<0.001)$ and lower LVEF $(45.4 \% \pm$ $12.7 \%, 52.4 \% \pm 10.4 \%, p<0.001)$, and were more frequently classified as Killip class II-IV AMI $(48.5 \%$ vs. $18.6 \%, p<0.001)$. Hypertension and diabetes mellitus were more frequently observed in the MACE group (53.2\% vs. $44.4 \%, p=0.025$; $38.9 \%$ vs. $26.5 \%, p<0.001)$. At the time of discharge, the use of beta blockers, angiotensin-converting enzyme inhibitors, and statins was less frequent in the MACE group
(83.1\% vs. $94.4 \%, \mathrm{p}<0.001 ; 83.6 \%$ vs. $95.9 \%, \mathrm{p}<0.001$; and $74.1 \%$ vs. $85.6 \%, p<0.001$; respectively). Comparison of baseline characteristics according to the formula for obtaining eGFR are provided in Supplementary Tables 1, 2.

\section{Creatinine Clearance/Estimated GFR}

The mean eGFR values on admission were $81.3 \pm 44.4$ and $78.5 \pm 27.1 \mathrm{~mL} /\left(\mathrm{min} / 1.73 \mathrm{~m}^{2}\right)$, as calculated with the MDRD Study and CKD-EPI formulas. The eGFRs calculated with both formulas were significantly lower in the MACE group than in the MACE-free group (MDRD Study equation: 63.5 \pm 47.7 $\mathrm{mL} /\left[\mathrm{min} / 1.73 \mathrm{~m}^{2}\right]$ vs. $84.5 \pm 43.1 \mathrm{~mL} /\left[\mathrm{min} / 1.73 \mathrm{~m}^{2}\right], \mathrm{p}<0.001$; CKD-EPI equation: $59.9 \pm 33.5 \mathrm{~mL} /\left[\mathrm{min} / 1.73 \mathrm{~m}^{2}\right]$ vs. $81.8 \pm 24.5$ $\left.\mathrm{mL} /\left[\mathrm{min} / 1.73 \mathrm{~m}^{2}\right], \mathrm{p}<0.001\right)$.

\section{Outcomes}

In Kaplan-Meier survival curve analysis, decreasing eGFRs were associated with increasing incidence rates of 1-year MACEs using both equations. The MDRD Study and CKD-EPI

Table 1. Baseline characteristics of the study subjects

\begin{tabular}{|c|c|c|c|c|}
\hline Characteristic & Total $(n=1,372)$ & Event free $(n=1,166)$ & Event $(n=206)$ & p-value \\
\hline \multicolumn{5}{|l|}{ Clinical characteristic } \\
\hline Age (yr) & $64.2 \pm 11.8$ & $63.3 \pm 11.6$ & $69.0 \pm 11.6$ & $<0.001$ \\
\hline Male sex & $931(67.9)$ & $802(68.8)$ & $129(62.6)$ & 0.096 \\
\hline Killip class II-IV & $317(23.1)$ & $217(18.6)$ & $100(48.5)$ & $<0.001$ \\
\hline \multicolumn{5}{|l|}{ Physical examination } \\
\hline $\mathrm{SBP}(\mathrm{mmHg})$ & $136.3 \pm 29.7$ & $137.3 \pm 28.4$ & $130.8 \pm 35.7$ & 0.019 \\
\hline Heart rate $(\mathrm{bpm})$ & $79.2 \pm 19.8$ & $77.9 \pm 18.8$ & $86.5 \pm 23.4$ & $<0.001$ \\
\hline \multicolumn{5}{|l|}{ Medical history } \\
\hline Hypertension & $623(45.7)$ & $515(44.4)$ & $108(53.2)$ & 0.025 \\
\hline Diabetes mellitus & $386(28.4)$ & $307(26.5)$ & $79(38.9)$ & $<0.001$ \\
\hline Smoking & $581(44.1)$ & $508(45.2)$ & $73(37.4)$ & 0.052 \\
\hline \multicolumn{5}{|c|}{ Laboratory or echocardiographic measure } \\
\hline Creatinine $(\mathrm{mg} / \mathrm{dL})$ & $1.1 \pm 1.1$ & $1.0 \pm 0.9$ & $1.8 \pm 1.9$ & $<0.001$ \\
\hline $\operatorname{MDRD} \operatorname{GFR}\left(\mathrm{mL} / \mathrm{min} / 1.73 \mathrm{~m}^{2}\right)$ & $81.3 \pm 44.4$ & $84.5 \pm 43.1$ & $63.5 \pm 47.7$ & $<0.001$ \\
\hline CKD-EPI GFR $\left(\mathrm{mL} / \mathrm{min} / 1.73 \mathrm{~m}^{2}\right)$ & $78.5 \pm 27.1$ & $81.8 \pm 24.5$ & $59.9 \pm 33.5$ & $<0.001$ \\
\hline LVEF (\%) & $51.6 \pm 10.9$ & $52.4 \pm 10.4$ & $45.4 \pm 12.7$ & $<0.001$ \\
\hline \multicolumn{5}{|l|}{ Medications } \\
\hline ACEi/ARB & $1,278(94.1)$ & $1,110(95.9)$ & $168(83.6)$ & $<0.001$ \\
\hline Beta-blockers & $1,258(92.7)$ & $1,091(94.4)$ & $167(83.1)$ & $<0.001$ \\
\hline Statin & $1,138(83.9)$ & $989(85.6)$ & $149(74.1)$ & $<0.001$ \\
\hline \multicolumn{5}{|l|}{ Type of myocardial infarction } \\
\hline NSTEMI & $756(55.1)$ & $637(54.6)$ & $119(57.8)$ & \multirow{2}{*}{0.448} \\
\hline STEMI & $616(44.9)$ & $529(45.4)$ & $87(42.2)$ & \\
\hline
\end{tabular}

Values are presented as mean \pm standard deviation or number (\%).

SBP, systolic blood pressure; MDRD, Modification of Diet in Renal Disease; GFR, glomerular filtration rate; CKD-EPI, Chronic Kidney Disease Epidemiology Collaboration; LVEF, left ventricular ejection fraction; ACEi, angiotensin-converting enzyme nhibitor; ARB, angiotensin receptor blocker; NSTEMI, non-ST elevation myocardial infarction; STEMI, ST elevation myocardial infarction. 
equations determined MACE incidence rates of $10.0 \%$ and $9.9 \%$ for $\mathrm{G} 1,10.2 \%$ and $9.0 \%$ for $\mathrm{G} 2,22.6 \%$ and $29.6 \%$ for
$\mathrm{G} 3$, and $45.4 \%$ and $44.9 \%$ for $\mathrm{G} 4 / \mathrm{G} 5(\mathrm{p}<0.001$ and $\mathrm{p}<0.001$, respectively; Fig. 1). There were statistically significant differ-

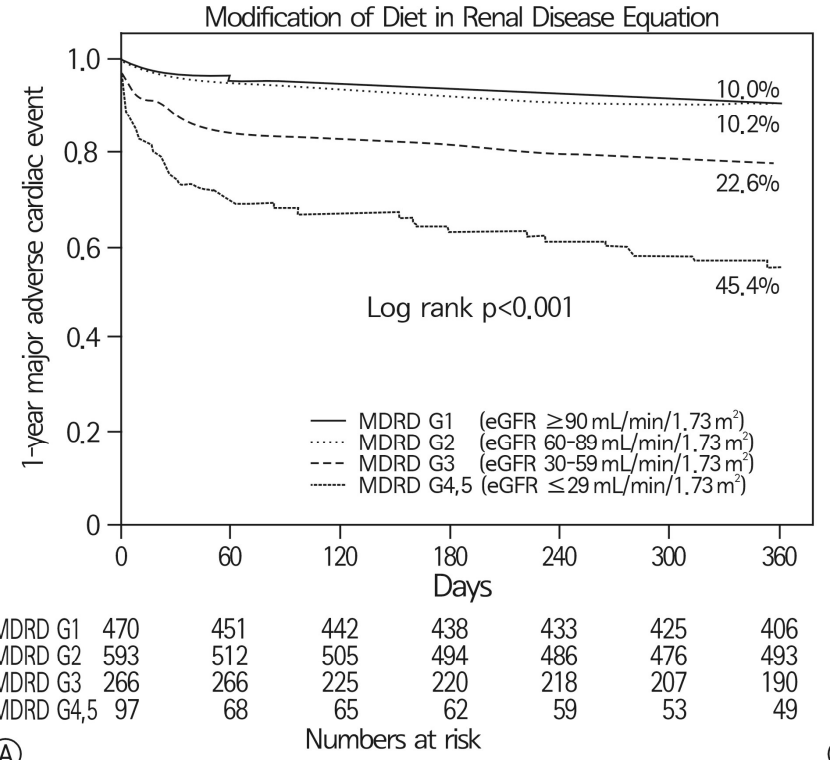

(A)

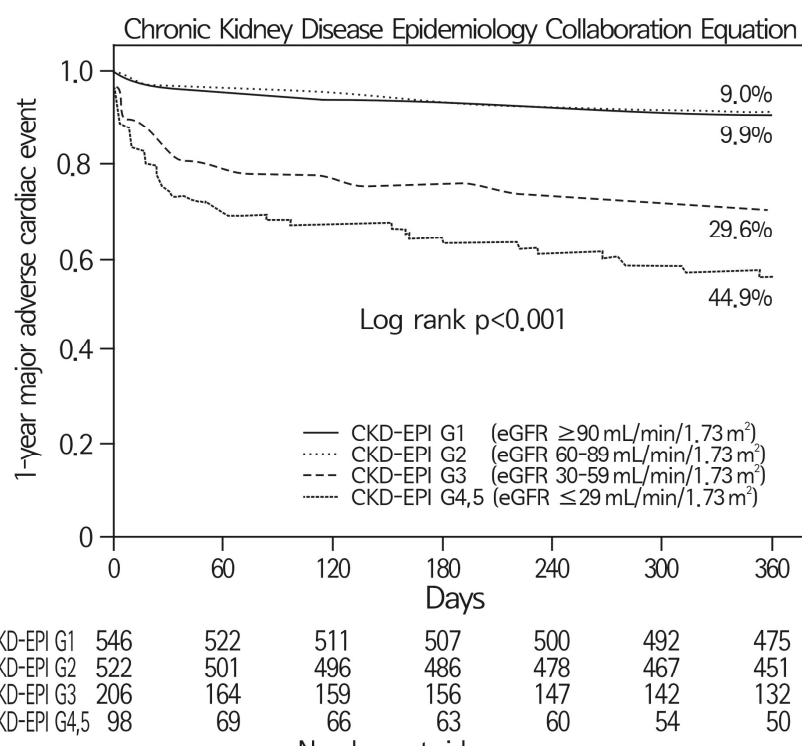

(B)

Numbers at risk

Fig. 1. Kaplan-Meier survival curve for 1-year major adverse cardiac events according to estimated glomerular filtration rate (eGFR) calculated with the simplified Modification of Diet in Renal Disease (MDRD) equation (A) and the Chronic Kidney Disease Epidemiology Collaboration (CKD-EPI) equation (B).

Table 2. Multivariate analysis using the Cox proportional hazards model for 1-year major adverse cardiac events in patients with acute myocardial infarction

\begin{tabular}{|c|c|c|c|c|c|c|}
\hline \multirow{2}{*}{ Variable } & \multicolumn{2}{|c|}{ Reference model } & \multicolumn{2}{|c|}{ MDRD model } & \multicolumn{2}{|c|}{ CKD-EPI model } \\
\hline & $\mathrm{HR}$ & $\mathrm{p}$-value & HR & p-value & HR & p-value \\
\hline \multicolumn{7}{|l|}{ Clinical characteristic } \\
\hline Age (yr) & $1.028(1.011-1.046)$ & 0.001 & $1.026(1.009-1.044)$ & 0.003 & $1.021(1.003-1.039)$ & 0.021 \\
\hline Male sex & $1.077(0.746-1.554)$ & 0.694 & $1.057(0.731-1.527)$ & 0.770 & $1.070(0.741-1.544)$ & 0.720 \\
\hline Killip class II-IV & $1.767(1.196-2.610)$ & 0.004 & $1.721(1.160-2.554)$ & 0.007 & $1.625(1.089-2.425)$ & 0.017 \\
\hline \multicolumn{7}{|l|}{ Physical examination } \\
\hline $\mathrm{SBP}(\mathrm{mmHg})$ & $0.998(0.991-1.004)$ & 0.427 & 0.997 (0.991-1.003) & 0.366 & $0.997(1.003-0.991)$ & 0.277 \\
\hline Heart rate (bpm) & $1.005(0.996-1.014)$ & 0.313 & $1.005(0.996-1.014)$ & 0.295 & $1.005(0.996-1.014)$ & 0.252 \\
\hline \multicolumn{7}{|l|}{ Medical history } \\
\hline Hypertension & $1.475(1.025-2.123)$ & 0.036 & $1.418(0.980-2.052)$ & 0.064 & $1.340(0.925-1.943)$ & 0.122 \\
\hline Diabetes mellitus & $1.176(0.815-1.698)$ & 0.387 & $1.131(0.779-1.644)$ & 0.517 & $1.066(0.720-1.557)$ & 0.742 \\
\hline \multicolumn{7}{|c|}{ Echocardiographic measure } \\
\hline LVEF (\%) & $0.969(0.953-0.984)$ & $<0.001$ & $0.971(0.955-0.987)$ & $<0.001$ & $0.973(0.957-0.990)$ & 0.001 \\
\hline \multicolumn{7}{|l|}{ Medications } \\
\hline ACEi/ARB & $0.473(0.279-0.800)$ & 0.005 & $0.495(0.290-0.845)$ & $<0.001$ & $0.556(0.322-0.960)$ & 0.035 \\
\hline Beta-blockers & $0.893(0.523-1.526)$ & 0.680 & $0.897(0.525-1.533)$ & 0.690 & $0.894(0.523-1.528)$ & 0.681 \\
\hline Statin & $0.692(0.452-1.059)$ & 0.090 & $0.706(0.461-1.081)$ & 0.109 & $0.731(0.477-1.121)$ & 0.151 \\
\hline \multicolumn{7}{|l|}{ GFR } \\
\hline MDRD & & & 0.997 (0.991-1.002) & 0.257 & & \\
\hline CKD-EPI & & & & & $0.991(0.983-0.998)$ & 0.015 \\
\hline
\end{tabular}

MDRD, Modification of Diet in Renal Disease; CKD-EPI, Chronic Kidney Disease Epidemiology Collaboration; HR, hazard ratio; SBP, systolic blood pressure; LVEF, left ventricular ejection fraction; ACEi, angiotensin-converting enzyme nhibitor; ARB, angiotensin receptor blocker; GFR, glomerular filtration rate; NSTEMI, non-ST elevation myocardial infarction; STEMI, ST elevation myocardial infarction. 
ences in cardiac death and myocardial infarction according to eGFR calculated with MDRD and CKD-EPI, but there was no statistically significant difference in revascularization between both groups (MDRD Study equation: $p=0.439$; CKD-EPI equation: $p=0.198$ ) (Supplementary Figs. 1-3).

In ROC curve analysis for prediction of 1-year MACE, the area under the curve (AUC) for the CKD-EPI equation was greater than that using the MDRD Study equation (AUC

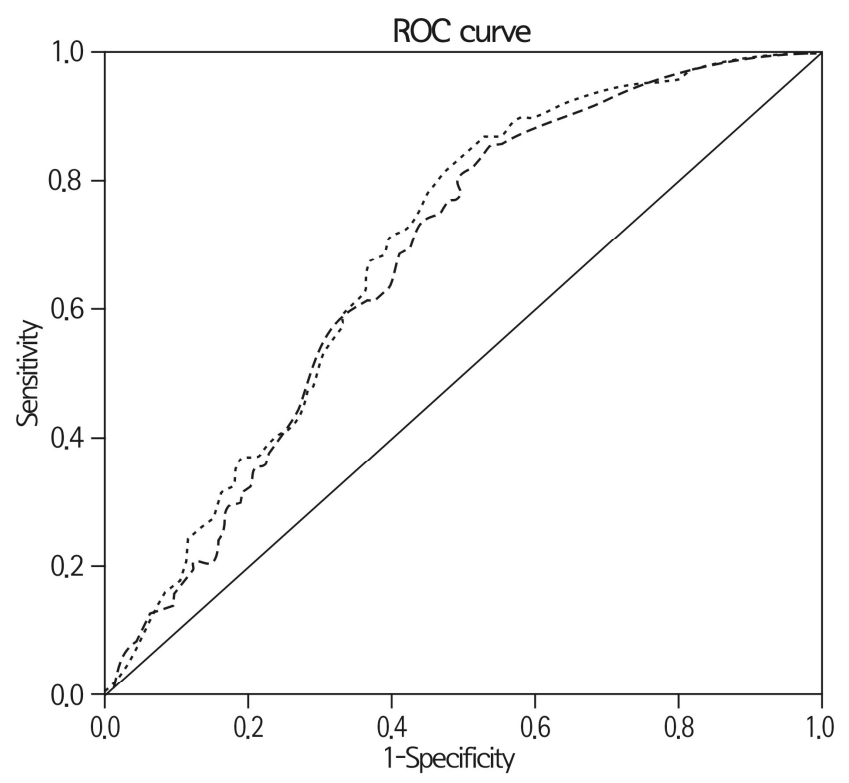

Diagonal segments are produced by ties

\begin{tabular}{|c|c|c|c|}
\hline & MDRD & CKD-EPI & $p$-value \\
\hline Area uncer the curve & 0.674 & 0.691 & 0.030 \\
\hline
\end{tabular}

Fig. 2. Receiver-operating characteristic (ROC) curve analysis for predicting 1-year major adverse cardiac events. MDRD, Modification of Diet in Renal Disease; CKD-EPI, Chronic Kidney Disease Epidemiology Collaboration.

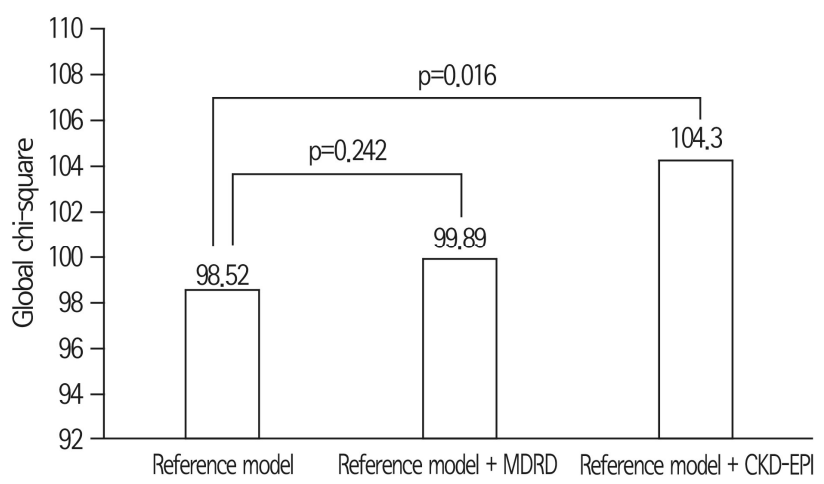

Fig. 3. Likelihood ratio test demonstrating the incremental predictive value of adding the estimated glomerular filtration rate calculated with the CKD-EPI equation to established risk factors of 1-year major adverse cardiac events. MDRD, Modification of Diet in Renal Disease; CKD-EPI, Chronic Kidney Disease Epidemiology Collaboration. for the CKD-EPI and MDRD Study equations: 0.691 and 0.674, respectively $[p=0.030]$ ) (Fig. 2$)^{11)}$.

In multivariate Cox proportional hazards analysis for 1-year MACEs, we used 2 models with independent predictors and eGFRs calculated with the MDRD Study and CKD-EPI equations. The eGFR based on the CKD-EPI equation could predict 1 -year prognosis in patients with AMI $(\mathrm{HR}, 0.991 ; 95 \% \mathrm{Cl}$, $0.983-0.998 ; p=0.015)$, whereas the MDRD Study equation could not (HR, 0.997; 95\% Cl, 0.991-1.002; $\mathrm{p}=0.257)$ (Table 2).

By using the likelihood ratio test and adding the GFR calculated with the CKD-EPI equation to the established risk factors, an incremental predictive value was obtained for 1-year MACEs $(p=0.016)$. However, the GFR calculated with the MDRD equation yielded a significant increment (Fig. 3).

\section{DISCUSSION}

Many studies have shown that CKD is an independent cardiovascular risk factor. These include the Studies of Left Ventricular Dysfunction (SOLVD), Survival and Ventricular Enlargement (SAVE), and Valsartan in Acute Myocardial Infarction (VALIANT) trials ${ }^{2,12,13)}$. The presence of renal dysfunction after $\mathrm{MI}$ has also been proven to increase the incidence rate of adverse outcomes ${ }^{14-16)}$. The mechanism by which renal impairment increases cardiovascular risk is not clear. Some studies suggest an association between atherosclerosis and endothelial dysfunction caused by oxidative stress, anemia, disturbed homeostasis of calcium phosphate, and inflammation $^{17-19)}$. Proteinuria, homocysteinemia, and uric acid are other risk factors that increase with renal decline ${ }^{20,21)}$.

Serum creatinine level was used for evaluating renal function. Considering that serum creatinine level is affected by age, sex, race, and lean body mass, it has limited value as a marker of renal function. Therefore, GFR has been generally used $^{22,23)}$. As GFR is difficult to assess, estimated GFR calculated by using equations has been widely used. In the SOLVD, SAVE, and VALIANT trials, the MDRD Study equation was used to estimate $\mathrm{GFR}^{2,12,13)}$.

The CKD-EPI equation has lower bias than the MDRD Study equation, especially at an eGFR of $>60 \mathrm{~mL} /\left(\mathrm{min} / 1.73 \mathrm{~m}^{2}\right)$. Its use could reduce the rate of false-positive diagnoses of CKD G3 (eGFR, <60 mL/[min/1.73 $\left.\left.\mathrm{m}^{2}\right]\right)$. In our study, the KaplanMeier survival curve showed the largest difference between the MDRD Study and CKD-EPI equations at CKD G3 $(22.6 \%$ vs. $29.6 \%$, respectively). This is possibly because many patients had a false-positive diagnosis of CKD G3.

This study had several clinical implications. First, it demonstrated that the eGFR calculated by using the CKD-EPI equation is not only a better index of kidney function but also has predictive value for long-term MACEs. In fact, the MDRD Study and Cockcroft-Gault formulas are more frequently used to calculate eGFR. Moreover, according to the current 
guidelines, the eGFR calculated with the MDRD Study equation is recommended for evaluation of kidney function in patients with acute coronary syndrome, as it takes race and sex into account ${ }^{24)}$. Assessment of the predictive value of eGFR calculated with the CKD-EPI formula for long-term MACEs is therefore crucial. Second, our study adds novel insight to a previous study that showed statistical significance for the predictive value of eGFR, as calculated with the CKD-EPI equation, but in a different manner. Third, to the best of our knowledge, this is the first study to demonstrate that eGFR calculated with the CKD-EPI formula could be a predictive indicator for the Korean population.

Our study has some limitations. First, the lack of data about percutaneous coronary intervention (PCI) and periprocedural complications was the greatest limitation of this study. Since MACE is affected by coronary angiographic characteristics, including features of treated vessels, length of lesion, and type of stent, further investigation is necessary, with use of precise data for $\mathrm{PCl}$ and non- $\mathrm{PCl}$ groups.

Second, the data were collected from a retrospective analysis in a single center. Although we used multivariate analysis to statistically control for selection bias, the possibility of residual confounding factors cannot be excluded completely. For example, the use of angiotensin-converting enzyme inhibitors/angiotensin receptor blockers and beta blockers, and the presence of hypertension, diabetes mellitus, and decreased LVEF were significantly greater in the event group than in the event-free group at baseline. This suggests that there were many confounding variables, even though multivariate analysis was used. Moreover, there were missing data for 9 patients. We excluded these from the analysis.

Fourth, only a maximum of 1 year of accumulated follow-up data were available for analysis, but evaluation of long-term prognosis is important. A follow-up study could provide useful data. Third, precise follow-up data on renal function were not available. Renal decline on follow-up could be an independent and important determinant of outcome ${ }^{25)}$.

In conclusion, decreased eGFR was closely related to increased incidence rate of 1-year MACEs, regardless of whether the MDRD Study or the CKD-EPI equation was used. The eGFR calculated with the CKD-EPI equation could be a predictive indicator, with incremental value, for the occurrence of 1-year MACEs as a prognostic factor in AMI.

Conflicts of Interest Disclosures: The researchers claim no conflicts of interest.

\section{Supplementary Materials}

Supplementary Tables and Figures can be found via http://www.e-agmr.org/src/sm/agmr.2017.21.1.10.

\section{REFERENCES}

1. Kim DH, Joung HJ, Kim SY, Ko WJ, Jin ES, Kim CJ. Clinical characteristics of elderly patients undergoing coronary angiography for chest pain. J Korean Geriatr Soc 2013;17:37-40.

2. Anavekar NS, McMurray JJ, Velazquez EJ, Solomon SD, Kober L, Rouleau JL, et al. Relation between renal dysfunction and cardiovascular outcomes after myocardial infarction. N Engl J Med 2004;351:1285-95.

3. Al Suwaidi J, Reddan DN, Williams K, Pieper KS, Harrington RA, Califf RM, et al. Prognostic implications of abnormalities in renal function in patients with acute coronary syndromes. Circulation 2002;106:974-80.

4. Sarnak MJ, Levey AS, Schoolwerth AC, Coresh J, Culleton B, Hamm LL, et al. Kidney disease as a risk factor for development of cardiovascular disease: a statement from the American Heart Association Councils on Kidney in Cardiovascular Disease, High Blood Pressure Research, Clinical Cardiology, and Epidemiology and Prevention. Circulation 2003;108:2154-69.

5. Levey AS, Bosch JP, Lewis JB, Greene T, Rogers N, Roth D. A more accurate method to estimate glomerular filtration rate from serum creatinine: a new prediction equation. Modification of Diet in Renal Disease Study Group. Ann Intern Med 1999; 130:461-70.

6. Levey AS, Coresh J, Greene T, Stevens LA, Zhang YL, Hendriksen $\mathrm{S}$, et al. Using standardized serum creatinine values in the modification of diet in renal disease study equation for estimating glomerular filtration rate. Ann Intern Med 2006;145: 247-54.

7. Levey AS, Stevens LA, Schmid CH, Zhang YL, Castro AF 3rd, Feldman HI, et al. A new equation to estimate glomerular filtration rate. Ann Intern Med 2009;150:604-12.

8. Thygesen K, Alpert JS, Jaffe AS, Simoons ML, Chaitman BR, White $\mathrm{HD}$, et al. Third universal definition of myocardial infarction. J Am Coll Cardiol 2012;60:1581-98.

9. Stevens LA, Coresh J, Feldman HI, Greene T, Lash JP, Nelson $\mathrm{RG}$, et al. Evaluation of the modification of diet in renal disease study equation in a large diverse population. J Am Soc Nephrol 2007;18:2749-57.

10. Stevens PE, Levin A; Kidney Disease: Improving Global Outcomes Chronic Kidney Disease Guideline Development Work Group Members. Evaluation and management of chronic kidney disease: synopsis of the kidney disease: improving global outcomes 2012 clinical practice guideline. Ann Intern Med 2013; 158:825-30.

11. Hasselbach W, Migala A. Calcium gradient dependent pyrophosphate formation by sarcoplasmic vesicles. Z Naturforsch C 1977;32:992-6.

12. Freeman RV, Mehta RH, Al Badr W, Cooper JV, Kline-Rogers $\mathrm{E}$, Eagle KA. Influence of concurrent renal dysfunction on outcomes of patients with acute coronary syndromes and implications of the use of glycoprotein IIb/IIIa inhibitors. J Am Coll Cardiol 2003;41:718-24.

13. Sørensen CR, Brendorp B, Rask-Madsen C, Køber L, Kjøller E, Torp-Pedersen C. The prognostic importance of creatinine clearance after acute myocardial infarction. Eur Heart J 2002; 23:948-52. 
14. Gibson CM, Pinto DS, Murphy SA, Morrow DA, Hobbach HP, Wiviott SD, et al. Association of creatinine and creatinine clearance on presentation in acute myocardial infarction with subsequent mortality. J Am Coll Cardiol 2003;42:1535-43.

15. Januzzi JL, Cannon CP, DiBattiste PM, Murphy S, Weintraub W, Braunwald E, et al. Effects of renal insufficiency on early invasive management in patients with acute coronary syndromes (The TACTICS-TIMI 18 Trial). Am J Cardiol 2002;90:1246-9.

16. McCullough PA. Beyond serum creatinine: defining the patient with renal insufficiency and why? Rev Cardiovasc Med 2003;4 Suppl 1:S2-6.

17. McCullough PA. Cardiorenal risk: an important clinical intersection. Rev Cardiovasc Med 2002;3:71-6.

18. Luft FC. Renal disease as a risk factor for cardiovascular disease. Basic Res Cardiol 2000;95 Suppl 1:I72-6.

19. Foley RN, Parfrey PS, Sarnak MJ. Epidemiology of cardiovascular disease in chronic renal disease. J Am Soc Nephrol 1998; 9(12 Suppl):S16-23.

20. National Kidney Foundation. K/DOQI clinical practice guidelines for chronic kidney disease: evaluation, classification, and stratification. Am J Kidney Dis 2002;39(2 Suppl 1):S1-266.

21. Luft FC. Renal disease as a risk factor for cardiovascular disease. Basic Res Cardiol 2000;95 Suppl 1:I72-6.

22. Walsh CR, O'Donnell CJ, Camargo CA Jr, Giugliano RP, LloydJones DM. Elevated serum creatinine is associated with 1-year mortality after acute myocardial infarction. Am Heart J 2002; 144:1003-11.

23. Shlipak MG. Pharmacotherapy for heart failure in patients with renal insufficiency. Ann Intern Med 2003;138:917-24.

24. Hamm CW, Bassand JP, Agewall S, Bax J, Boersma E, Bueno $\mathrm{H}$, et al. ESC Guidelines for the management of acute coronary syndromes in patients presenting without persistent ST-segment elevation: The Task Force for the management of acute coronary syndromes (ACS) in patients presenting without persistent ST-segment elevation of the European Society of Cardiology (ESC). Eur Heart J 2011;32:2999-3054.

25. Hsieh MJ, Chen YC, Chen CC, Wang CL, Wu LS, Wang CC. Renal dysfunction on admission, worsening renal function, and severity of acute kidney injury predict 2-year mortality in patients with acute myocardial infarction. Circ J 2013;77:217-23. 
Supplement Table 1. Baseline characteristics of the study subjects according to the eGFR calculated with the MDRD Study equation

\begin{tabular}{|c|c|c|c|c|c|}
\hline Variable & $\begin{array}{c}\text { MDRD G1 } \\
(\mathrm{n}=471)\end{array}$ & $\begin{array}{c}\text { MDRD G2 } \\
(\mathrm{n}=542)\end{array}$ & $\begin{array}{c}\text { MDRD G3 } \\
(n=270)\end{array}$ & $\begin{array}{c}\begin{array}{c}\text { MDRD G45 } \\
(\mathrm{n}=98)\end{array} \\
\end{array}$ & $\mathrm{p}$-value \\
\hline \multicolumn{6}{|l|}{ Clinical characteristic } \\
\hline Age (yr) & $59.7 \pm 11.7$ & $64.2 \pm 11.2$ & $69.4 \pm 10.7$ & $70.7 \pm 8.9$ & $<0.001$ \\
\hline Male sex & $309(65.6)$ & 379 (69.9) & $185(68.5)$ & $63(64.3)$ & 0.427 \\
\hline Killip class II-IV & $56(11.9)$ & $109(20.1)$ & $95(35.2)$ & $59(60.2)$ & $<0.001$ \\
\hline \multicolumn{6}{|l|}{ Physical examination } \\
\hline $\mathrm{SBP}(\mathrm{mmHg})$ & $138.6 \pm 26.2$ & $135.8 \pm 29.3$ & $130.9 \pm 31.3$ & $143.3 \pm 40.7$ & 0.002 \\
\hline Heart rate (bpm) & $77.7 \pm 17.6$ & $78.6 \pm 18.6$ & $83.2 \pm 23.2$ & $83.6 \pm 26.0$ & $<0.001$ \\
\hline \multicolumn{6}{|l|}{ Medical history } \\
\hline Hypertension & $174(37.2)$ & $230(42.6)$ & $150(56.4)$ & $73(75.3)$ & $<0.001$ \\
\hline Diabetes mellitus & $104(22.3)$ & $128(23.8)$ & $99(37.4)$ & $56(57.1)$ & $<0.001$ \\
\hline Smoking & $223(48.6)$ & $251(48.4)$ & $86(34.0)$ & $24(5.8)$ & $<0.001$ \\
\hline \multicolumn{6}{|c|}{ Laboratory or echocardiographic measure } \\
\hline Creatinine (mg/dL) & $0.7 \pm 0.1$ & $0.9 \pm 0.1$ & $1.3 \pm 0.3$ & $4.2 \pm 2.7$ & $<0.001$ \\
\hline $\mathrm{eGFR}\left(\mathrm{mL} / \mathrm{min} / 1.73 \mathrm{~m}^{2}\right)$ & $119.5 \pm 51.7$ & $76.0 \pm 8.5$ & $48.3 \pm 8.8$ & $17.1 \pm 7.8$ & $<0.001$ \\
\hline LVEF (\%) & $54.1 \pm 9.3$ & $51.6 \pm 10.5$ & $49.2 \pm 12.4$ & $43.8 \pm 12.3$ & $<0.001$ \\
\hline \multicolumn{6}{|l|}{ Medications } \\
\hline ACEi/ARB & $454(96.4)$ & $521(96.1)$ & $235(87.0)$ & $73(74.5)$ & $<0.001$ \\
\hline Beta-blockers & $446(95.3)$ & 505 (93.9) & $233(88.9)$ & $78(82.1)$ & $<0.001$ \\
\hline Statin & $398(85.0)$ & $459(85.3)$ & $218(82.9)$ & $68(72.3)$ & 0.013 \\
\hline \multicolumn{6}{|c|}{ Type of myocardial infarction } \\
\hline NSTEMI & $236(50.1)$ & $301(55.5)$ & $146(54.1)$ & $74(75.5)$ & \multirow{2}{*}{0.001} \\
\hline STEMI & $234(49.7)$ & $240(44.3)$ & $122(45.2)$ & $24(24.5)$ & \\
\hline
\end{tabular}

Values are presented as mean \pm standard deviation or number (\%).

eGFR, estimated glomerular filtration rate; MDRD, Modification of Diet in Renal Disease; SBP, systolic blood pressure; LVEF, left ventricular ejection fraction; ACEi, angiotensin-converting enzyme nhibitor; ARB, angiotensin receptor blocker; NSTEMI, non-ST elevation myocardial infarction; STEMI, ST elevation myocardial infarction. 
Supplement Table 2. Baseline characteristics of the study subjects according to the eGFR calculated with the CKD-EPI equation

\begin{tabular}{|c|c|c|c|c|c|}
\hline Variable & $\begin{array}{c}\text { CKD-EPI G1 } \\
(\mathrm{n}=471)\end{array}$ & $\begin{array}{c}\text { CKD-EPI G2 } \\
(\mathrm{n}=542)\end{array}$ & $\begin{array}{c}\begin{array}{c}\text { CKD-EPI G3 } \\
(\mathrm{n}=270)\end{array} \\
\end{array}$ & $\begin{array}{c}\text { CKD-EPI G45 } \\
(\mathrm{n}=98)\end{array}$ & p-value \\
\hline \multicolumn{6}{|l|}{ Clinical characteristics } \\
\hline Age (yr) & $57.2 \pm 10.2$ & $67.0 \pm 10.6$ & $72.1 \pm 9.4$ & $71.1 \pm 8.9$ & $<0.001$ \\
\hline Male sex & $405(73.8)$ & 349 (66.7) & $122(58.7)$ & $60(59.4)$ & 0.427 \\
\hline Killip class II-IV & $65(11.8)$ & $108(20.7)$ & $89(42.8)$ & $57(56.4)$ & $<0.001$ \\
\hline \multicolumn{6}{|l|}{ Physical examination } \\
\hline SBP (mmHg) & $139.5 \pm 26.3$ & $134.7 \pm 28.2$ & $129.8 \pm 34.1$ & $142.9 \pm 40.4$ & 0.002 \\
\hline Heart rate (bpm) & $76.9 \pm 16.6$ & $79.2 \pm 19.3$ & $83.1 \pm 24.4$ & $84.7 \pm 26.3$ & $<0.001$ \\
\hline \multicolumn{6}{|l|}{ Medical history } \\
\hline Hypertension & $201(36.9)$ & $230(44.3)$ & $122(58.7)$ & $74(74.7)$ & $<0.001$ \\
\hline Diabetes mellitus & $122(22.4)$ & $124(24.1)$ & $83(39.9)$ & $58(58.0)$ & $<0.001$ \\
\hline Smoking & $283(53.7)$ & $218(43.3)$ & $62(31.5)$ & $21(21.9)$ & $<0.001$ \\
\hline \multicolumn{6}{|c|}{ Laboratory or echocardiographic measure } \\
\hline Creatinine $(\mathrm{mg} / \mathrm{dL})$ & $0.7 \pm 0.2$ & $0.9 \pm 0.2$ & $1.4 \pm 0.3$ & $4.1 \pm 2.7$ & $<0.001$ \\
\hline eGFR $\left(\mathrm{mL} / \mathrm{min} / 1.73 \mathrm{~m}^{2}\right)$ & $102.2 \pm 11.4$ & $77.7 \pm 8.5$ & $47.2 \pm 8.6$ & $17.0 \pm 8.0$ & $<0.001$ \\
\hline LVEF (\%) & $54.1 \pm 9.2$ & $51.3 \pm 10.7$ & $47.8 \pm 13.1$ & $44.8 \pm 12.1$ & $<0.001$ \\
\hline \multicolumn{6}{|l|}{ Medications } \\
\hline ACEi/ARB & $527(96.0)$ & $503(96.2)$ & $180(86.5)$ & $73(72.3)$ & $<0.001$ \\
\hline Beta-blockers & $518(95.2)$ & $488(94.2)$ & $181(88.7)$ & $75(77.3)$ & $<0.001$ \\
\hline Statin & $471(86.6)$ & $442(85.2)$ & $159(78.3)$ & $71(73.2)$ & 0.001 \\
\hline \multicolumn{6}{|c|}{ Type of myocardial infarction } \\
\hline NSTEMI & $282(51.4)$ & $284(54.3)$ & $114(54.8)$ & $77(76.2)$ & \multirow{2}{*}{$<0.001$} \\
\hline STEMI & $265(48.3)$ & $239(45.7)$ & $93(44.7)$ & $23(22.8)$ & \\
\hline
\end{tabular}

Values are presented as mean \pm standard deviation or number (\%).

CKD-EPI: Chronic Kidney Disease Epidemiology Collaboration; SBP, systolic blood pressure; eGFR, estimated glomerular filtration rate; LVEF, left ventricular ejection fraction; ACEi, angiotensin-converting enzyme nhibitor; ARB, angiotensin receptor blocker; NSTEMI, non-ST elevation myocardial infarction; STEMI, ST elevation myocardial infarction. 

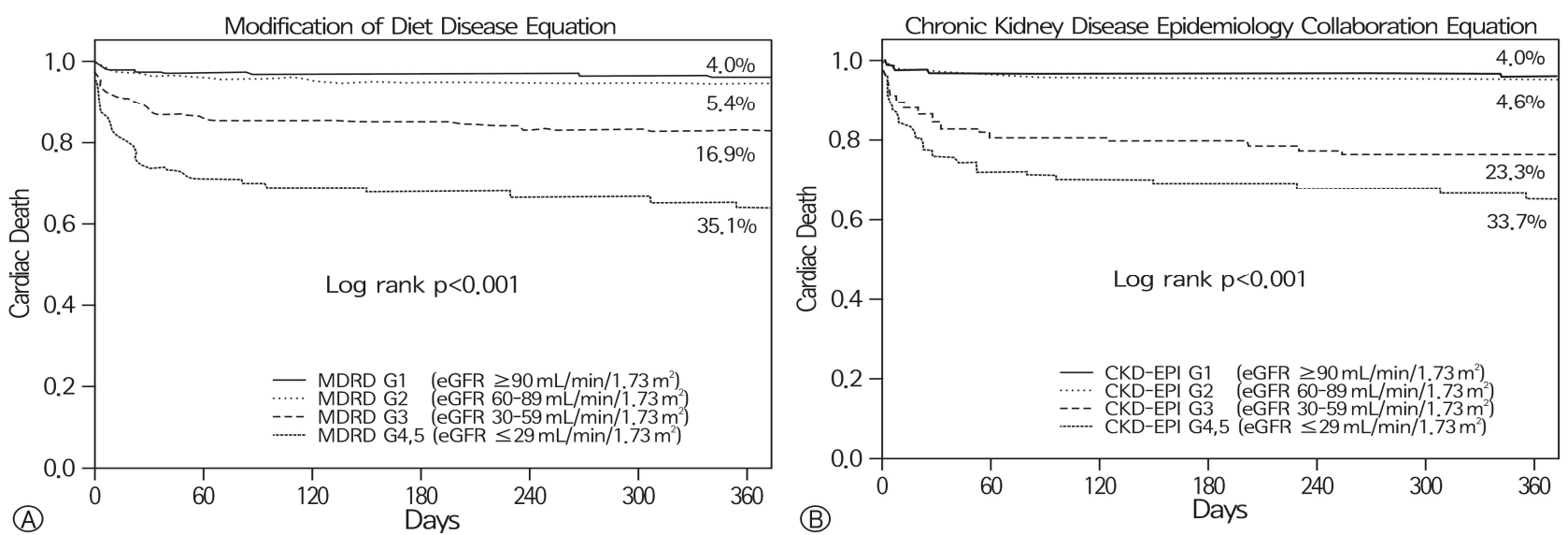

Supplementary Fig. 1. Kaplan-Meier survival curve for cardiac death according to estimated glomerular filtration rate (eGFR) calculated with the simplified Modification of Diet in Renal Disease (MDRD) equation (A) and the Chronic Kidney Disease Epidemiology Collaboration (CKD-EPI) equation (B).
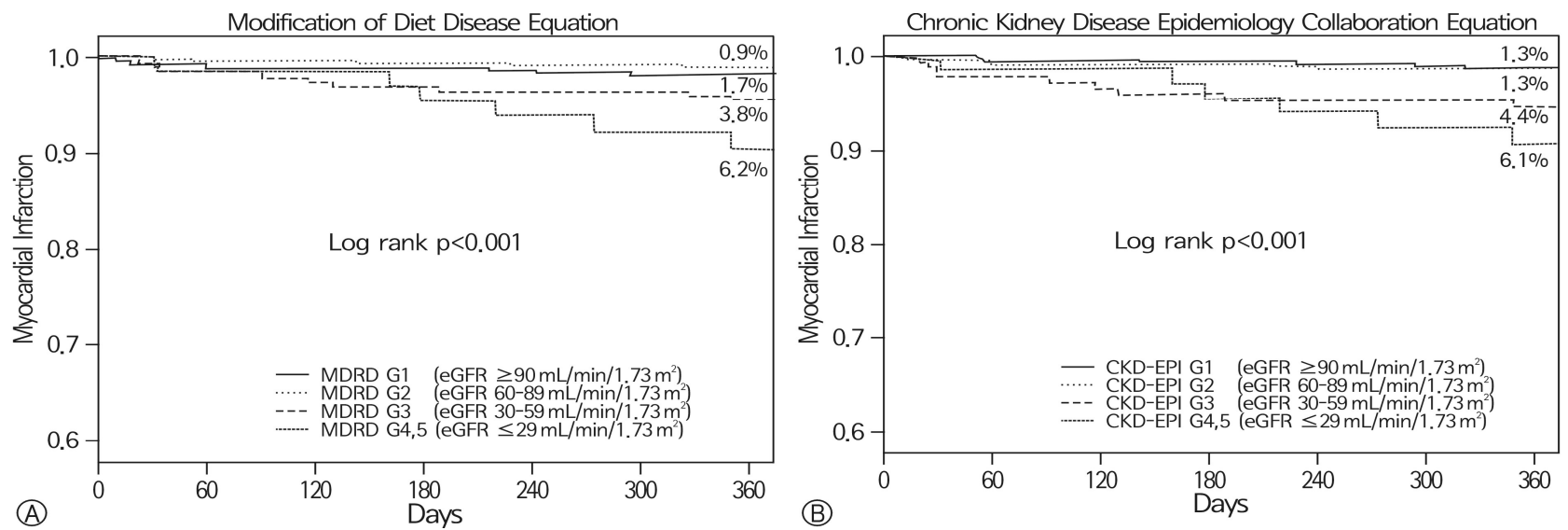

Supplementary Fig. 2. Kaplan-Meier survival curve for myocardial infarction according to estimated glomerular filtration rate (eGFR) calculated with the simplified Modification of Diet in Renal Disease (MDRD) equation (A) and the Chronic Kidney Disease Epidemiology Collaboration (CKD-EPI) equation (B).
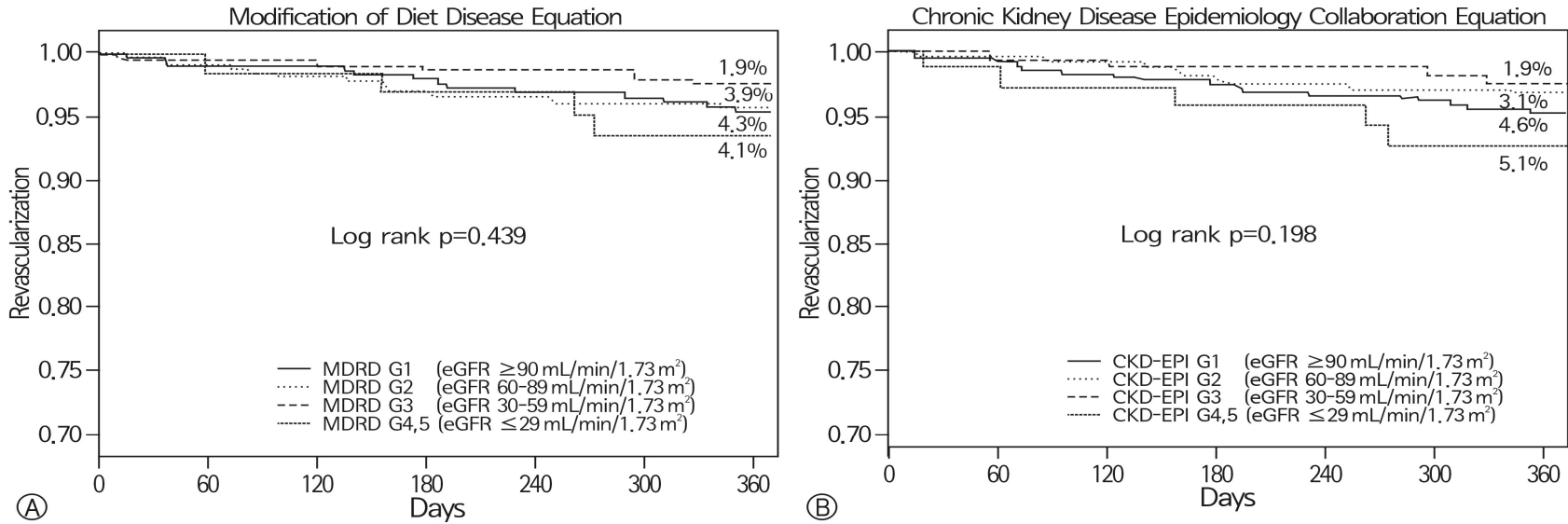

Supplementary Fig. 3. Kaplan-Meier survival curve for revascularization according to estimated glomerular filtration rate (eGFR) calculated with the simplified Modification of Diet in Renal Disease (MDRD) equation (A) and the Chronic Kidney Disease Epidemiology Collaboration (CKD-EPI) equation (B). 